\title{
Tumor suppressor role of miR-3622b-5p in ERBB2-positive
}

\section{cancer}

\author{
Mingjie Lu, ${ }^{1, *}$, Tongshan Wang ${ }^{1, *}$, Mingfeng He ${ }^{2, *}$, Wenfang Cheng ${ }^{3}$, Ting Yan ${ }^{4}$, Zebo \\ Huang ${ }^{1}$, Lan Zhang ${ }^{1}$, Huo Zhang ${ }^{1}$, Wei Zhu ${ }^{1}$, Yichao Zhu ${ }^{5,6}$, Ping Liu ${ }^{1}$ \\ ${ }^{1}$ Department of Oncology, First Affiliated Hospital of Nanjing Medical University, Nanjing 210029, PR China \\ ${ }^{2}$ Department of Anesthesiology, First Affiliated Hospital of Nanjing Medical University, Nanjing 210029, PR China \\ ${ }^{3}$ Department of Gastroenterology, First Affiliated Hospital of Nanjing Medical University, Nanjing 210029, PR China \\ ${ }^{4}$ Safety Assessment and Research Center for Drug, Pesticide and Veterinary Drug of Jiangsu Province, Nanjing Medical \\ University, Nanjing 211166, PR China \\ ${ }^{5}$ Department of Physiology, Nanjing Medical University, Nanjing 211166, PR China \\ ${ }^{6}$ State Key Laboratory of Reproductive Medicine, Nanjing Medical University, Nanjing 211166, PR China \\ *These authors have contributed equally to this work \\ Correspondence to: Wei Zhu, email: zhuwei@njmu.edu.cn \\ Yichao Zhu, email: zhuyichao@njmu.edu.cn \\ Ping Liv, email: liu-ping@csco.org.cn
}

Keywords: miR-3622b-5p, ERBB2, cancer, proliferation, apoptosis

Received: July 18, $2016 \quad$ Accepted: January 10,2017 Published: February 01, 2017

\section{ABSTRACT}

Over-expression or amplification of ERBB2 is observed in multifarious carcinomas. However, the molecular mechanism of ERBB2 downregulation in ERBB2-positive cancers remains obscure. This experiment investigated the suppressive role of miR$3622 b-5 p$ in ERBB2-positive breast and gastric cancers. The luciferase activity of ERBB2 3'-untranslated region-based reporters constructed in HEK-293T, SK-BR-3 and MCF-10A cells suggested that ERBB2 was the target gene of miR-3622b-5p. Overexpressed miR-3622b-5p reduced the protein level of ERBB2, weakened the activation of mTORC1/S6, and induced the apoptosis of ERBB2-positive cancer cells. MiR-3622b$5 p$ was significantly down-regulated in breast and gastric cancer tissues. This downregulation in ERBB2-positive breast and gastric cancer tissues was more obvious than that in ERBB2-negative breast and gastric cancer tissues. MiR-3622b-5p turned ERBB2-positive cancer cells more vulnerable to the apoptosis induced by cisplatin and 5-fluorouracil. Taken together, $\mathrm{miR}-3622 \mathrm{~b}-5 \mathrm{p}$ is involved in the proliferation and apoptosis of human ERBB2-positive cancer cells via targeting ERBB2/mTORC1 signaling pathway.

\section{INTRODUCTION}

Over-expression of human epidermal growth factor receptor 2 (ERBB2 or Her2) contributes to the malignant progression of tumors [1], especially the tumors of colon, bladder, ovary, endometrium, lung, uterine cervix, head and neck, and stomach [2-8]. As a molecular abnormality triggered by gene amplification, ERBB2 over-expression occurs in about $25 \%$ of breast carcinomas and a subset of aggressive tumors [9]. Mounting evidence proves that ERBB2 over-expression in gastric cancer leads to poor prognosis [10]. Although ERBB2-targetd therapy (trastuzumab or herceptin) has been used to treat ERBB2- overexpressing tumors [11, 12], patients' drug resistance thwarts its clinical wide spread [13].

MicroRNAs (miRNAs) are essential to cancer cell survival, proliferation, differentiation, migration, invasion and metastasis [14-16]. MiRNA subtypes, including miR548d-3p, miR-559, miR-125a, miR-125b, miR-205, miR155 and miR-4728, target ERBB2 and are downregulated in cancers [17-20]. However, the specific mechanism of miRNA in ERBB2-positive cancers is still unknown. This experiment demonstrated for the first time that the level of miR-3622b-5p was inversely correlated with the level of ERBB2 expression in human ERBB2-positive tumors, and that miR-3622b-5p induced the apoptosis of breast 
and gastric cancer cells by repressing ERBB2 expression. MiR-3622b-5p made ERBB2-positive cancer cells more susceptible to the apoptosis induced by cisplatin and 5-fluorouracil. Collectively, these findings conclude that miR-3622b-5p is a regulator of ERBB2 in ERBB2positive cancers.

\section{RESULTS}

\section{ERBB2 as the target gene of miR-3622b-5p}

TargetScan Human (http://www.targetscan.org) suspects that ERBB2 is the target gene of the miR-18-5p, miR-125-5p, miR-133a-3p or miR-3622b-5p. To explore whether ERBB2 is the target gene of those miRNAs, we transfected miR-18-5p, miR-125-5p, miR-133a-3p or miR-3622b-5p mimic and miRNA mimic control into SKBR-3 or SNU-216 cells. Consequently, the expression of ERBB2 in miR-3622b-5p-transfected cells, not in cells transfected with miR-18-5p, miR-125-5p or miR-133a-3p, was more significantly depressed than that in control cells (Figure 1A and Supplementary Figure 1). Meanwhile, the over-expression of miR-3622b-5p did not alter the expression level of ERBB3 in SK-BR-3 and SNU-216 cells (Figure 1A).

Next, we constructed the luciferase reporter vectors at the putative ERBB2 3'-UTR target site (ERBB2-3'UTR-WT) or the fragment of ERBB2 3'-UTR lacking the candidate miR-3622b-5p binding sequence (ERBB23 '-UTR-del) for the miR-3622b-5p downstream of the luciferase gene (Figure 1B). Luciferase reporter vectors, miR-3622b-5p mimic or the miRNA mimic control were transfected into HEK-293T cells, respectively. For HEK$293 \mathrm{~T}$ cells, a significant decrease of luciferase activity became notable when ERBB2-3'-UTR-WT was cotransfected with miR-3622b-5p mimic, but this decrease did not show up in the ERBB2-3'-UTR-del group (Figure 1C). After transfecting luciferase reporters into MCF-10A or SK-BR-3 cells, ERBB2-3'-UTR-del up-regulated the relative luciferase activity more obviously compared to the ERBB2-3'-UTR-WT group (Figure 1D and 1E). Taken together, these results show that ERBB2 is the target gene of miR-3622b-5p.

\section{MiR-3622b-5p suppressed mTOR signaling in ERBB2-positive cancer cells}

ERBB2 induction of migration and invasiveness of cancer cells require the activation of small GTPases and mTORC1 signaling [21-23]. We examined the activation of RhoA, Rac1 and mTORC1 signaling in miR-3622b5p-transfected cells and control ERBB2-positive cells. As a result, the activations of RhoA and Rac1 were not significantly changed in miR-3622b-5p-transfected cells compared to those in control SK-BR-3 or SNU-216 cells (Figure 2A and 2B). However, phosphorylation of S6, the direct downstream of mTORC1 signaling, was obviously down-regulated in miR-3622b-5p-transfected cells (Figure $2 \mathrm{C})$. These results suggest that miR-3622b-5p downregulates the $\mathrm{mTORC} 1$ signaling, not Rho signaling, in ERBB2-positive cancer cell lines.

\section{MiR-3622b-5p inhibited the proliferation and induced the apoptosis of ERBB2-positive cancer cells}

MTORC1 controls the cell growth and body homeostasis [24]. Clonogenic assay revealed that SK-BR-3 and SNU-216 cells transfected with miR$3622 b-5 p$ mimic exhibited a significant decrease of clones, and this decrease could be reversed by the overexpression of ERBB2 lacking the 3'-UTR (Figure 3). Moreover, SK-BR-3 and SNU-216 cells transfected with miR-3622b-5p mimic exhibited significant apoptosis that could be reversed by the over-expression of ERBB2 lacking the $3{ }^{-}$-UTR (Figure 4). Collectively, these results suggest that $\mathrm{miR}-3622 \mathrm{~b}-5 \mathrm{p}$ inhibits the proliferation and induces the apoptosis of ERBB2positive cancer cells.

\section{MiR-3622b-5p was down-regulated in ERBB2-positive cancer tissues}

MiR-3622b-5p expression in breast cancer tissues and gastric cancer tissues was examined by quantitative real-time PCR. To analyze the expression in breast cancer tissues, samples were made with cancer tissues of 112 patients and adjacent normal tissues of 30 patients. To analyze the expression in gastric cancer tissues, samples were made with gastric tissues of 71 patients and tumor adjacent normal tissues of 30 patients. According to the results, miR-3622b-5p expression was significantly down-regulated in cancer tissues, compared with that in tumors' adjacent normal tissues, respectively (Figure 5A and $5 \mathrm{~B}$ ). We also found that miR-3622b-5p expression was significantly down-regulated in SK-BR-3 breast cancer cells compared with that in MCF-10A normal human mammary epithelial cells (Supplementary Figure 2).

Meanwhile, the association between miR-3622b$5 p$ and ERBB2 expression was explored by testing the miR-3622b-5p expression in 40 patients' ERBB2-positive breast cancer tissues and 72 patients' ERBB2-negative breast cancer tissues, and in 17 patients' ERBB2-positive gastric cancer tissues and 54 patients' ERBB2-negative gastric cancer tissues. The results showed that miR$3622 \mathrm{~b}-5 \mathrm{p}$ was significantly down-regulated in human ERBB2-positive cancer tissues, compared with that in ERBB2-negative cancer tissues (Figure 6A and 6B). Taken together, these findings indicate that the miR-3622b-5p level is inversely correlated with ERBB2 expression in epithelial tumors. 

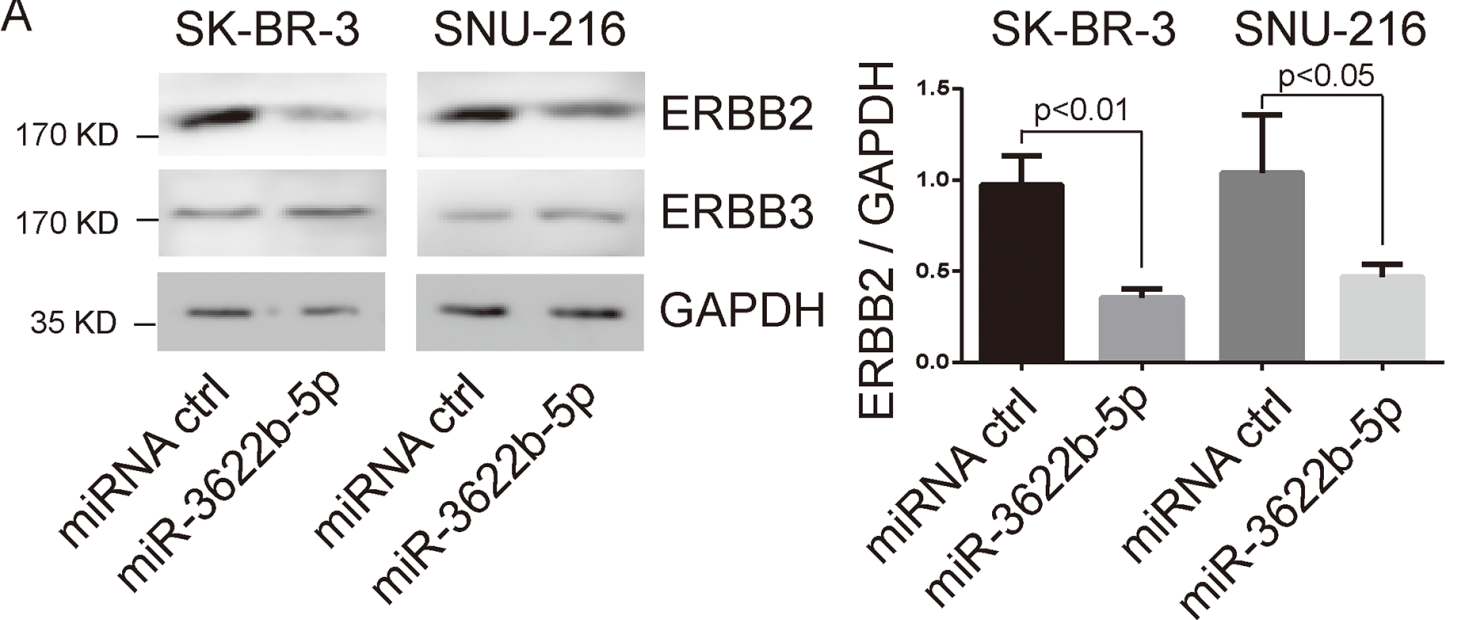

B

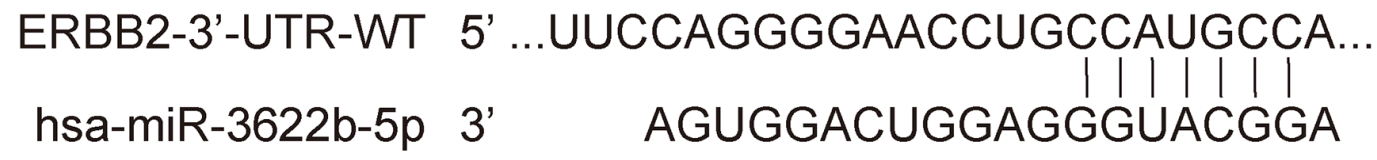

ERBB2-3'-UTR-del 5' ...UUCCAGGGGAACCUG A...
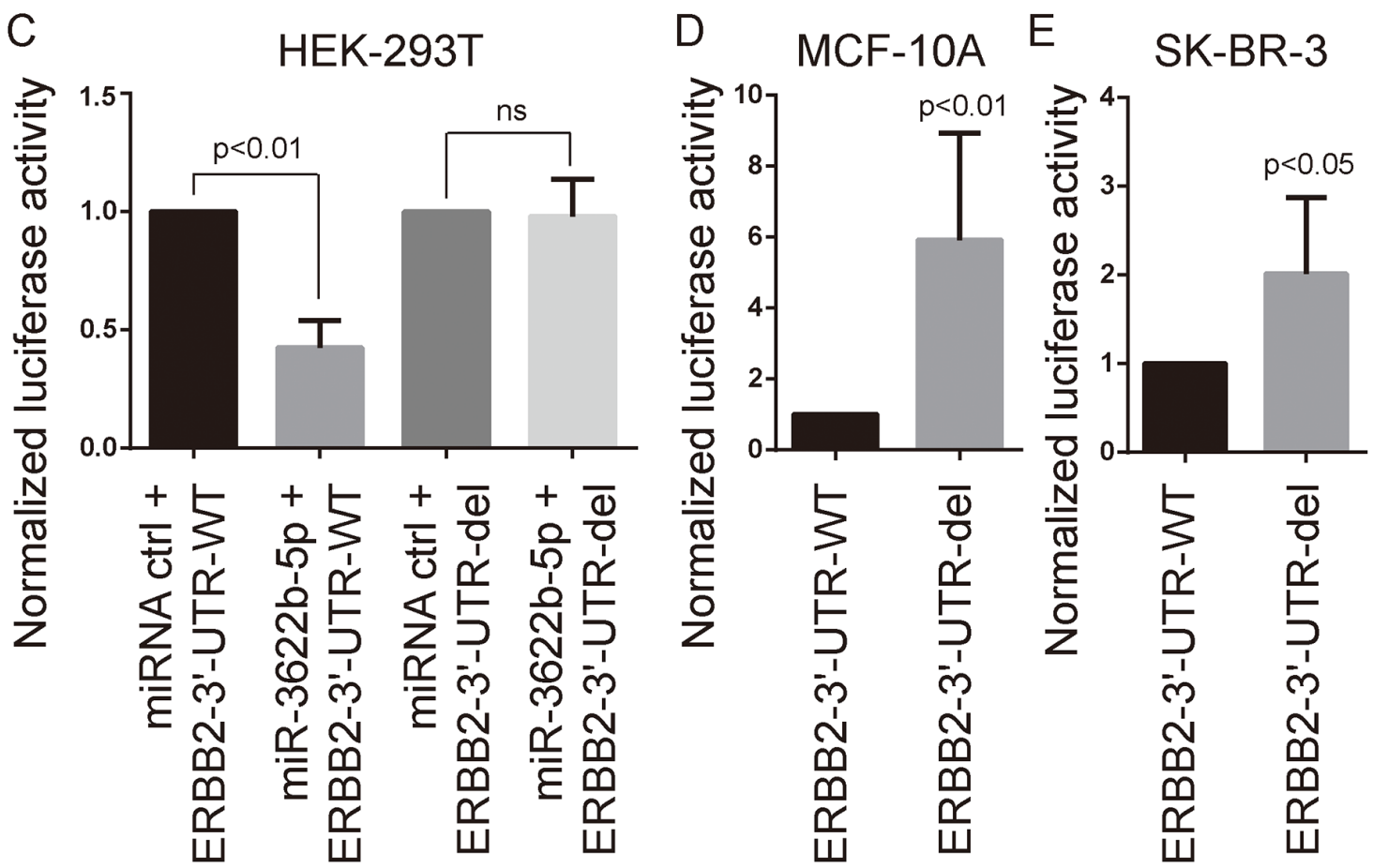

Figure 1: ERBB2 as target of miR-3622-5p. A. Western blot analysis showing suppressed ERBB2 protein levels in SK-BR-3 breast cancer cells and SNU-216 gastric cancer cells after miR-3622-5p over-expression. The over-expression of miR-3622-5p does not alter the expression level of ERBB3. GAPDH as the internal control. Graphical presentation in the right panel. B. The seed sequence of miR-3622b-5p is complementary to the 3'-UTR of ERBB2. C. Luciferase assay showing reduction in reporter activity (relative luciferase units) after co-transfection of wild type ERBB2 3'-UTR (ERBB2-3'UTR-WT) or the fragment of ERBB2 3'-UTR lacking the candidate miR-3622b-5p binding sequence (ERBB2-3'-UTR-del) with miR-3622-5p into HEK-293T cells. ns, no significance. D. Luciferase assay showing reduction in reporter activity after transfection of ERBB2-3'UTR-WT or ERBB2-3'-UTR-del in MCF-10A cells. E. Luciferase assay showing reduction in reporter activity after transfection of ERBB2-3'UTR-WT or ERBB2-3'-UTR-del in SK-BR-3 cells. 
MiR-3622b-5p turned ERBB2-positive cancer cells more vulnerable to the apoptosis induced by cisplatin and 5-fluorouracil

Since miR-3622b-5p induces the apoptosis of ERBB2-positive cancer cells, it is proposed that miR3622b-5p might evoke the apoptosis of ERBB2-positive cancer cells by weakening drug resistance. To confirm this hypothesis, drug-induced apoptosis in chemotherapy was evaluated through transfecting SK-BR-3 and SNU-216 cells with miR-3622b-5p mimic. According to MTT assay, cells transfected with miR-3622b-5p mimic exhibited greatly decreased resistance to cisplatin and 5-fluorouracil (5-FU) compared with cells transfected with miRNA
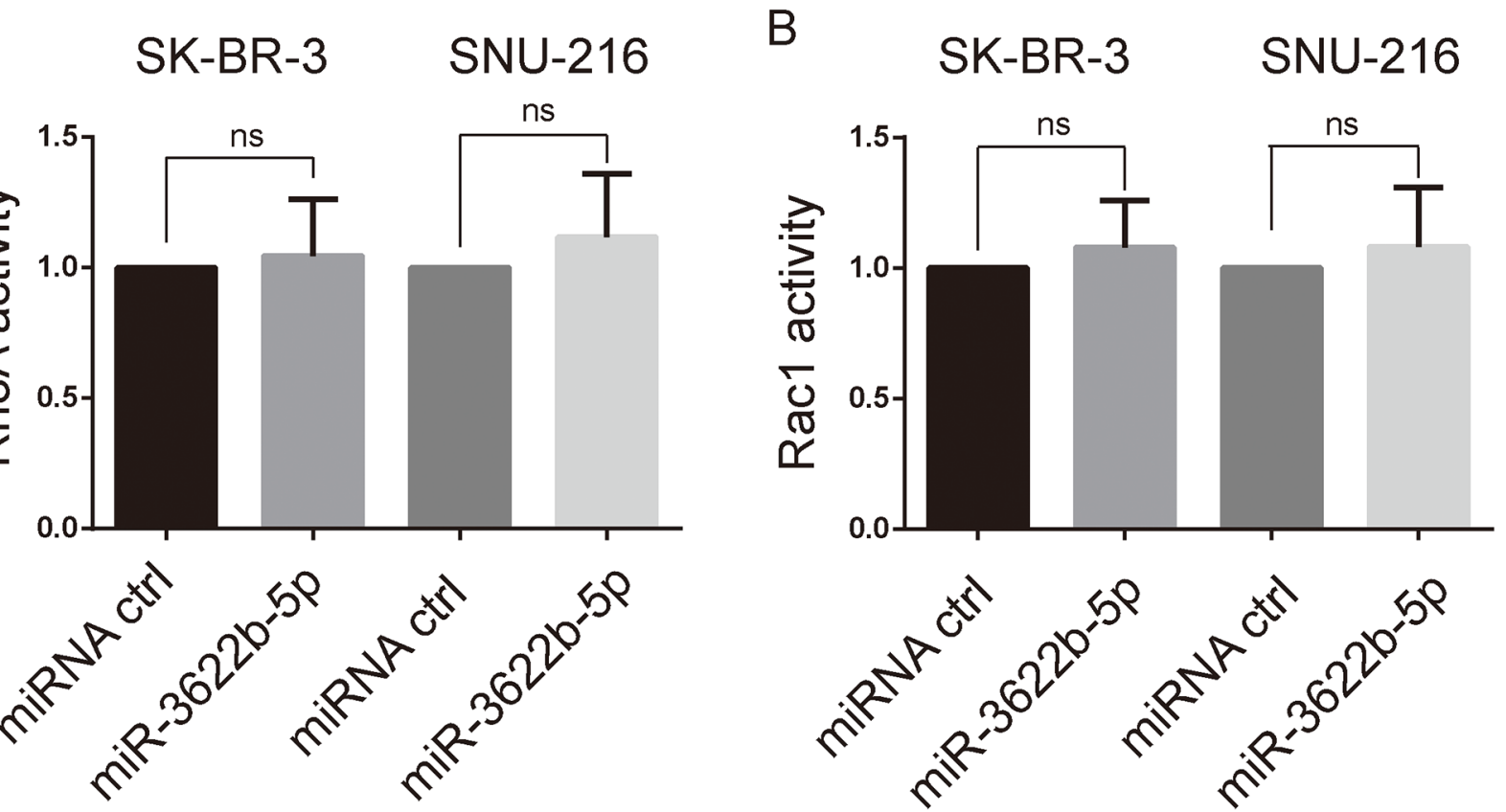

C
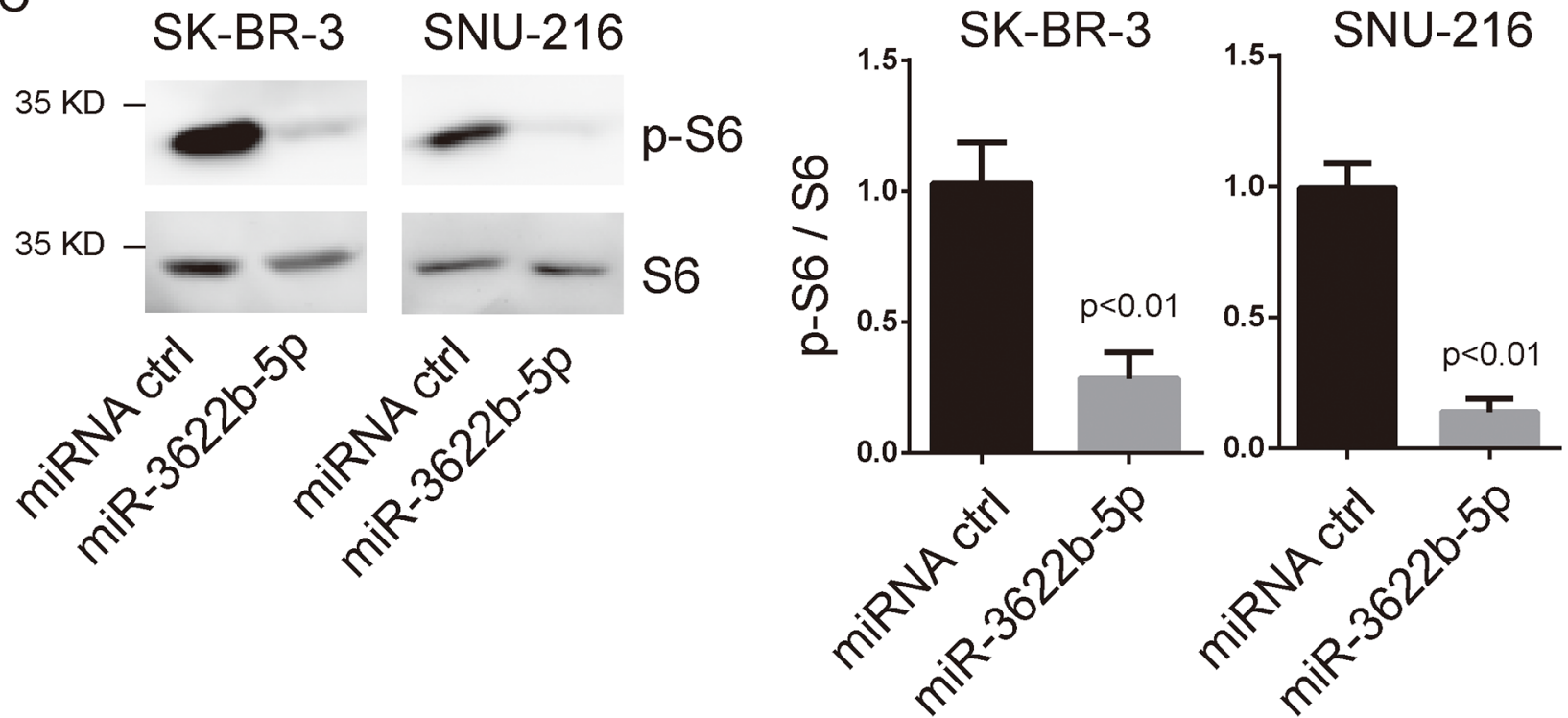

Figure 2: MiR-3622b-5p suppresses mTORC1 signaling. A. and B. miR-3622b-5p overexpression did not alter the activation of RhoA and Rac1 in SK-BR-3 breast cancer cells and SNU-216 gastric cancer cells. The RhoA or Rac1 relative active levels were normalized to the average value of SK-BR-3 or SNU-216 cells transfected with control miRNA. ns, no significance. C. miR-3622b-5p overexpression suppresses the phosphorylation of S6 in SK-BR-3 breast cancer cells and SNU-216 gastric cancer cells. Graphical presentation in the right panel. 
A

\section{miRNA-Ctrl}

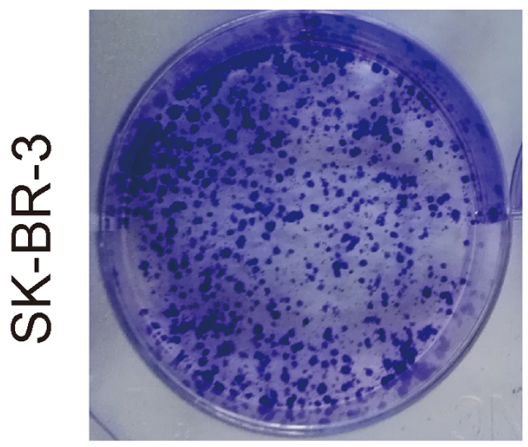

B

miRNA-Ctrl

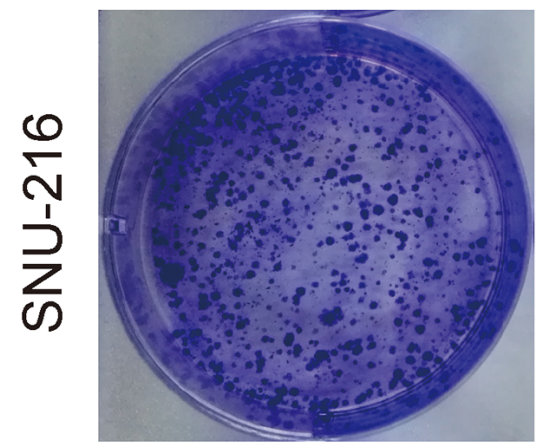

miRNA-3622b-5p

+ERBB2
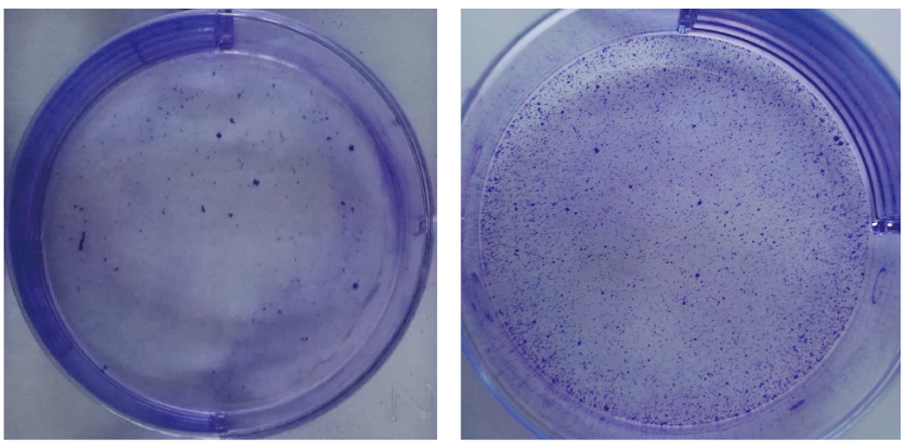

miRNA-3622b-5p + ERBB2
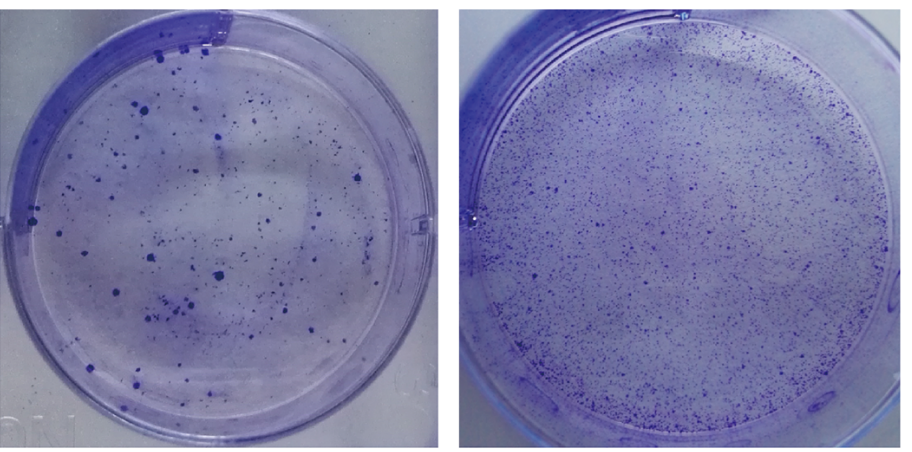

C

SK-BR-3
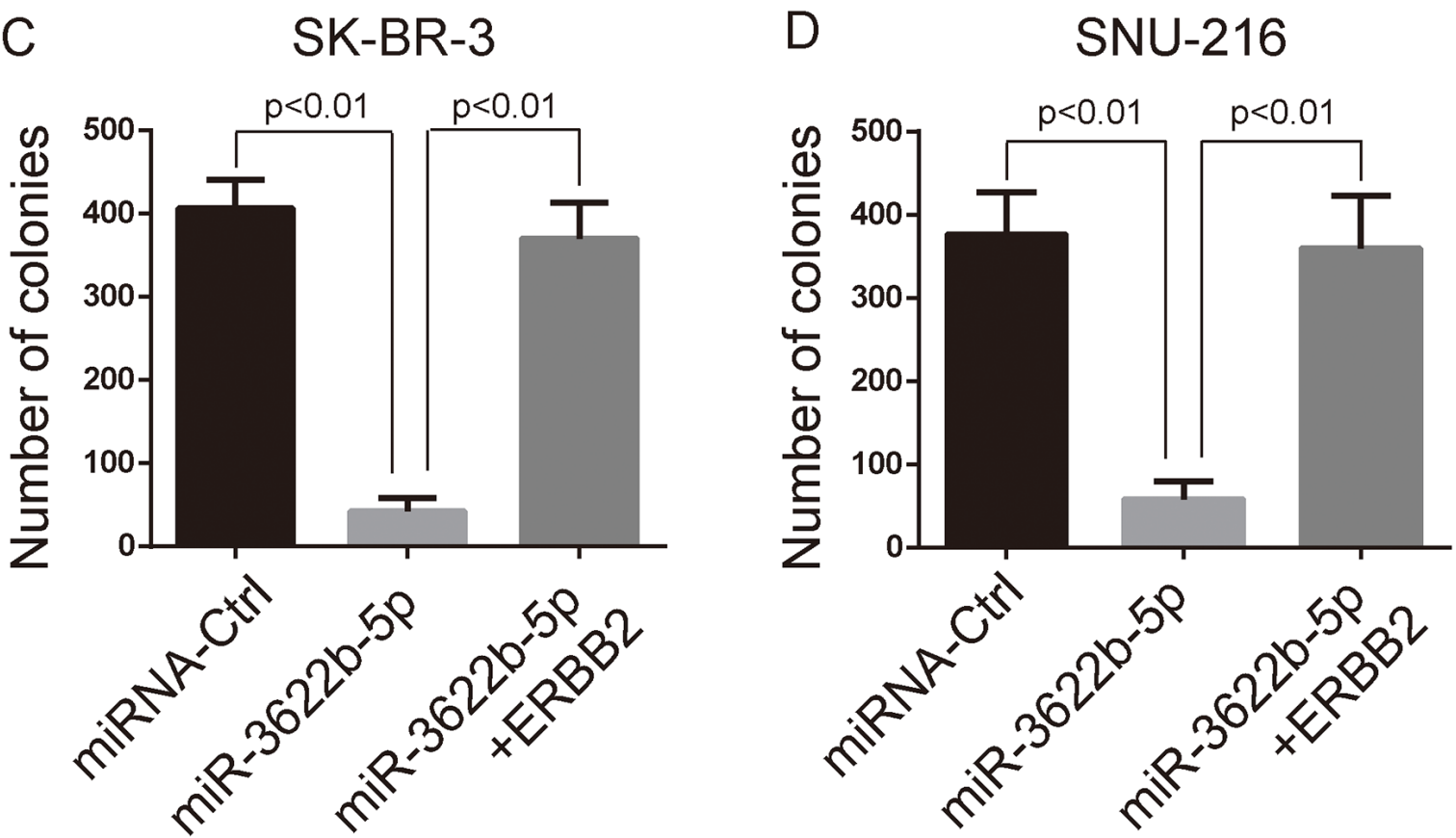

Figure 3: MiR-3622b-5p suppresses the colony formation ability of ERBB2-positive cancer cells. MiR-3622b-5p overexpression reduced the colony formation ability of SK-BR-3 breast cancer cells A. and C. or SNU-216 gastric cancer cells B. and $\mathbf{D}$. which could be reversed by the over-expression of ERBB2 lacking the 3'-UTR. The number of colonies was counted and shown in panel C and D. 
A

\section{miRNA-Ctrl}
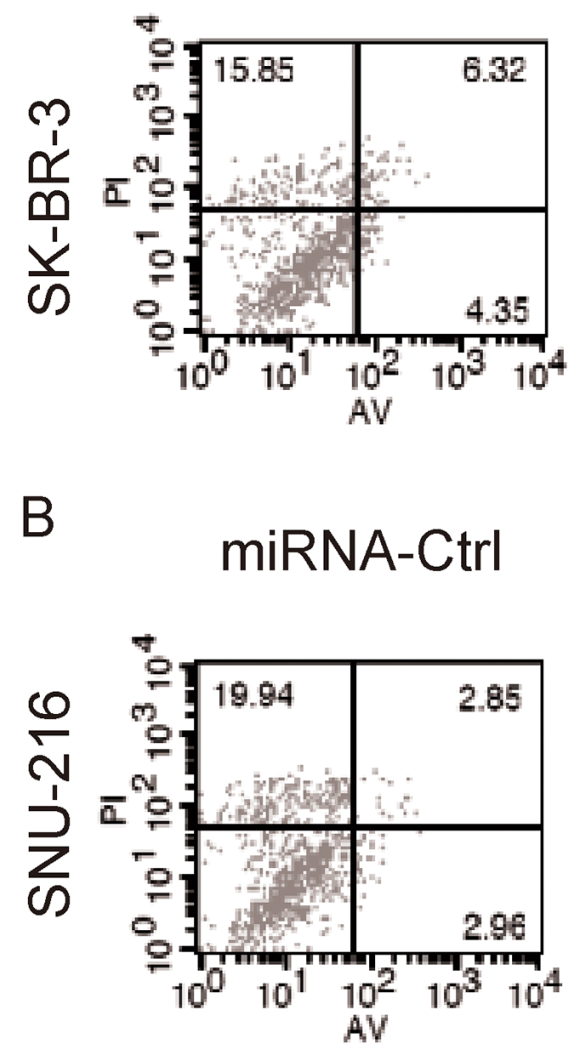

C
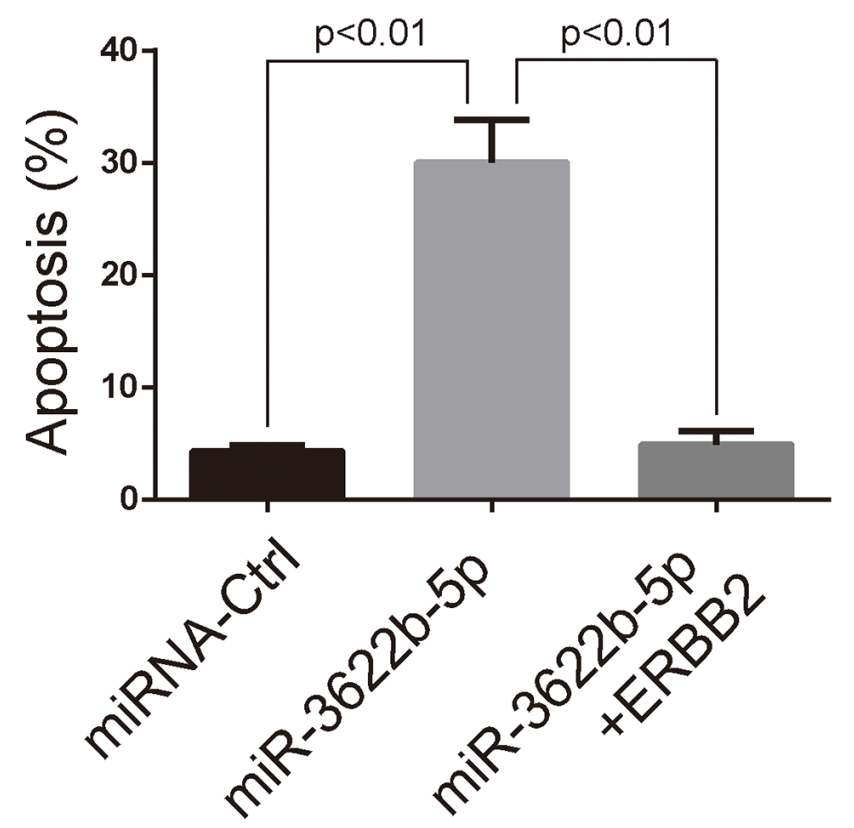

miRNA-3622b-5p

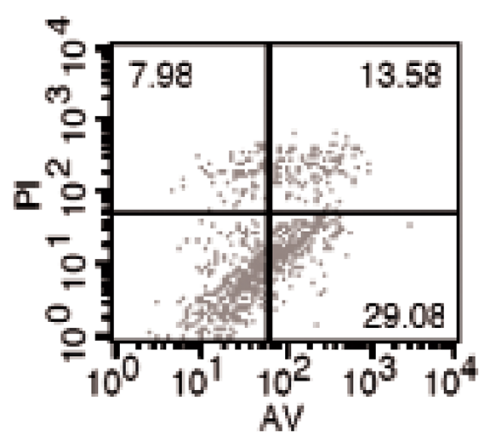

miRNA-3622b-5p

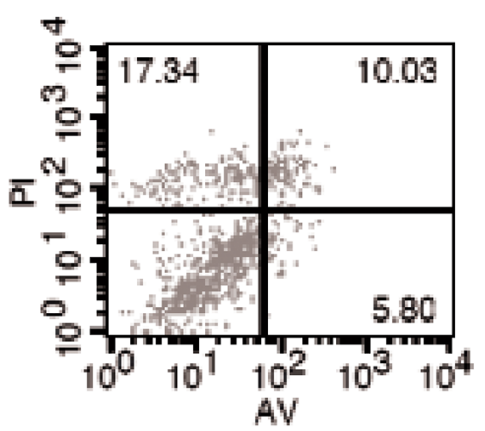

miRNA-3622b-5p + ERBB2

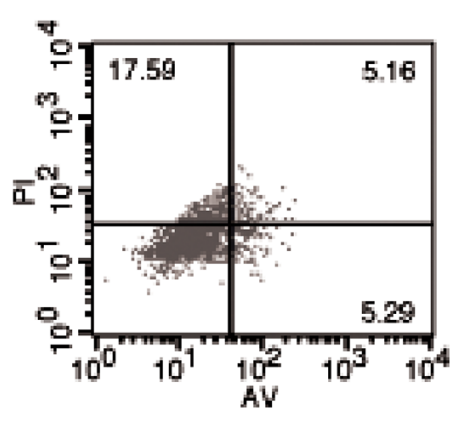

miRNA-3622b-5p +ERBB2

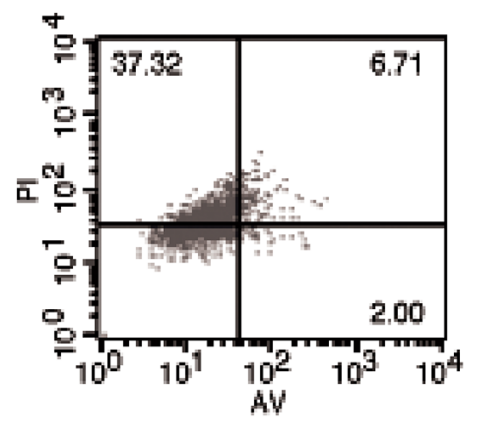

D SNU-216
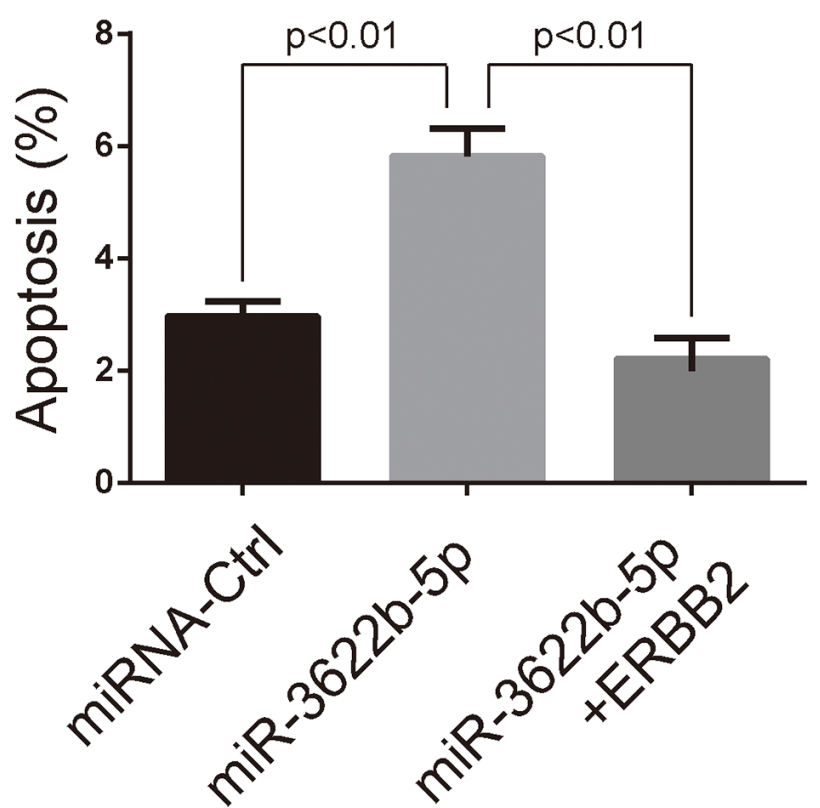

Figure 4: MiR-3622b-5p induces the apoptosis of ERBB2-positive cancer cells. MiR-3622b-5p over-expression induced the apoptosis of SK-BR-3 breast cancer cells A. and C. or SNU-216 gastric cancer cells B. and D. which could be reversed by the overexpression of ERBB2 lacking the 3'-UTR. The percent of apoptotic cells (AnnexinV-positive and PI-negative cells) was shown in panel $\mathrm{C}$ and D. 
mimic control (Figure 7A and 7B). These results suggest that miR-3622b-5p weakens the resistance of ERBB2positive cancer cells against cisplatin and 5-FU.

\section{DISCUSSION}

MiR-21 signaling sustains epithelial-tomesenchymal transition (EMT) in ERBB2-positive breast cancer [25]. MiR-125b is down-regulated in metastatic breast cancers and there is a positive correlation between ERBB2/HER2 level and erythropoietin receptor (as a target of miR-125b) level [26]. MiR-221 enhances the resistance against trastuzumab and the metastasis of
ERBB2-positive breast cancer by targeting PTEN [27]. The expression of ERBB2 is inversely correlated with the level of miR-155 (a well-documented oncogenic miRNA) in ERBB2-positive breast tumors [19]. In this experiment, miR-3622b-5p was down-regulated in ERBB2-positive cancer tissues, suggesting its suppressive role in ERBB2positive cancer.

When trastuzumab, small molecular targeted drug CP724714, or interfering RNA against ERBB2 are applied, the EMT-like phenotype of gastric cancer cells is dramatically reversed [28]. In breast cancer, the combination of 5-fluorouracil and cisplatin/docetaxel can trigger pathologic complete response, particularly in HER2-
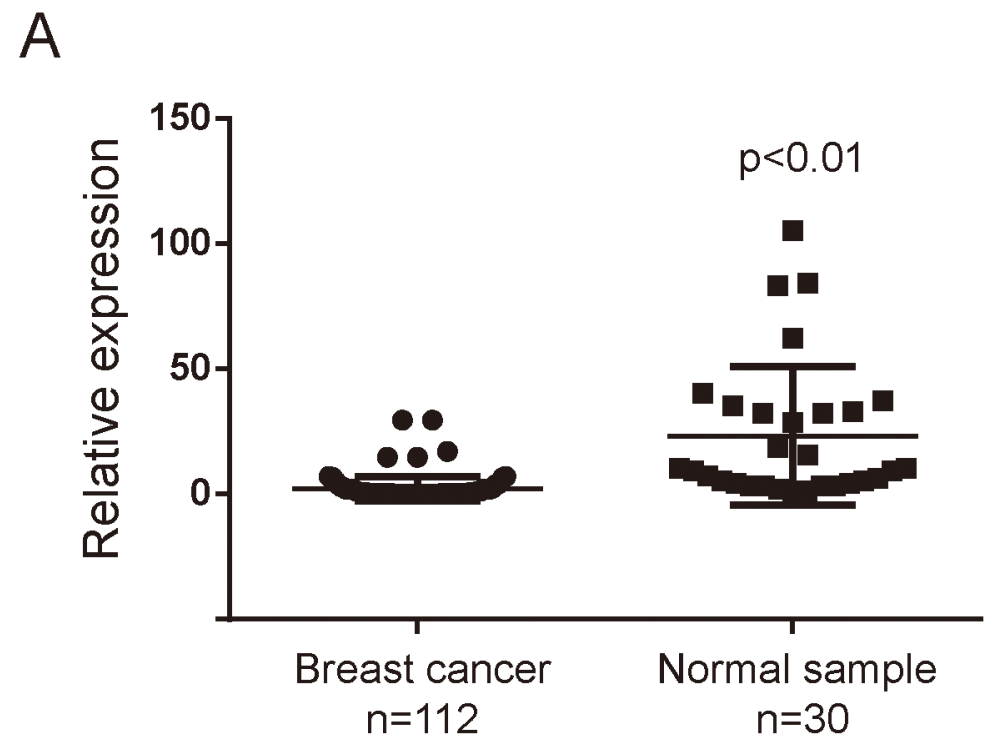

B

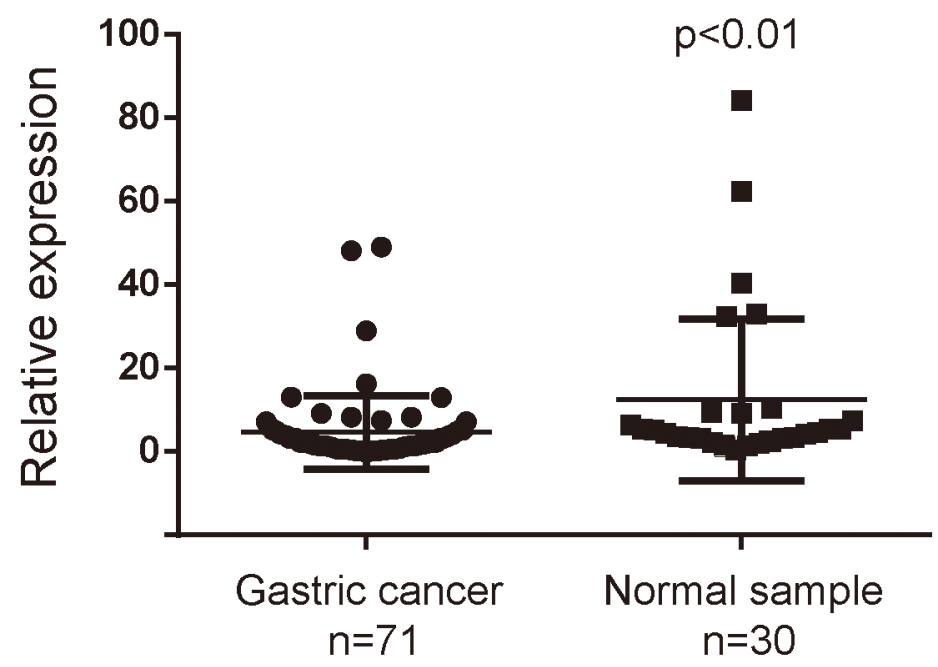

Figure 5: MiR-3622b-5p is down-regulated in cancer tissues. The miR-3622-5p expression was suppressed in a majority of breast cancer samples when compared to normal breast samples A. or in a majority of gastric cancer samples when compared to normal gastric samples B. The miRNA relative expression levels were normalized to the average value of breast cancer samples (A) or gastric cancer samples (B). 
positive and triple-negative diseases [29]. The combination of irinotecan, 5-fluorouracil, leucovorin (FOLFIRI) and trastuzumab is curative for recurrent metastatic gastric cancer [30]. In this study, miR-3622b-5p made ERBB2positive cancer cells more vulnerable to the apoptosis induced by cisplatin and 5-FU. Therefore, miR-3622b-5p can be taken as a novel target of chemotherapeutic agents.
In conclusion, miR-3622b-5p is involved in the proliferation and apoptosis of ERBB2-positive cancer cells via targeting ERBB2/mTORC1 signaling pathway. Therefore, miR-3622b-5p is a tumor suppressor in ERBB2-positive cancers and a potential diagnostic marker and therapeutic target for human ERBB2-positive cancers.

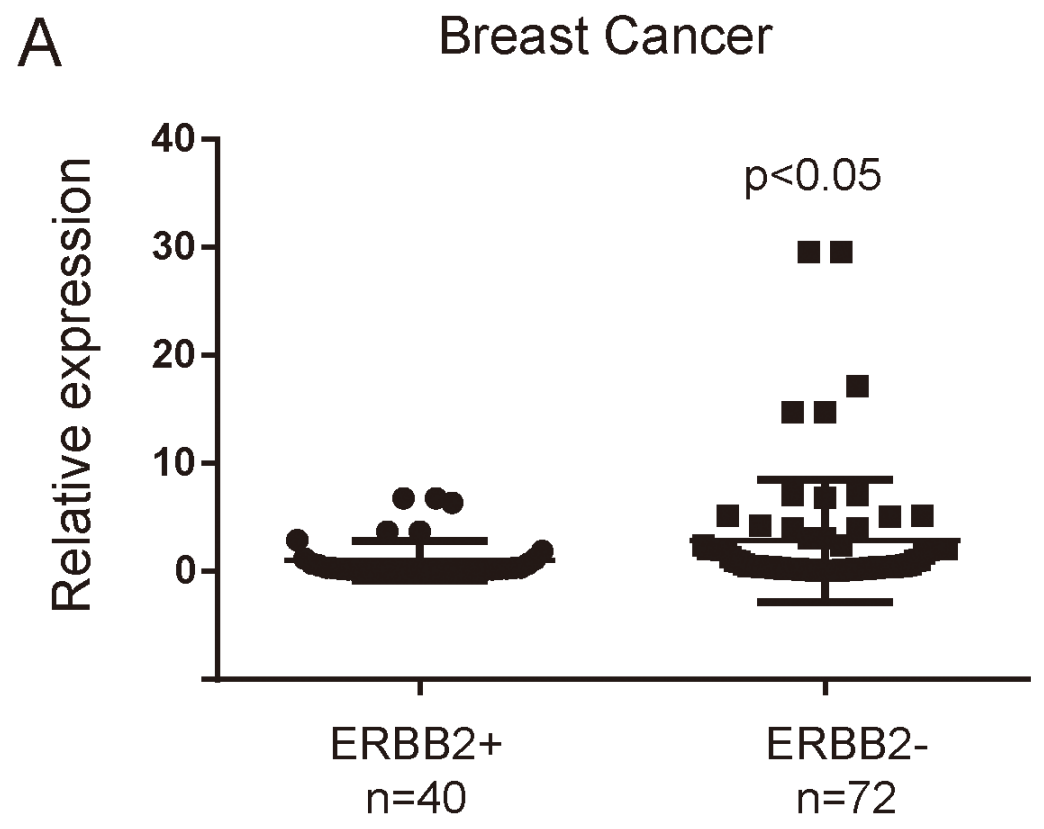

B

Gastric Cancer

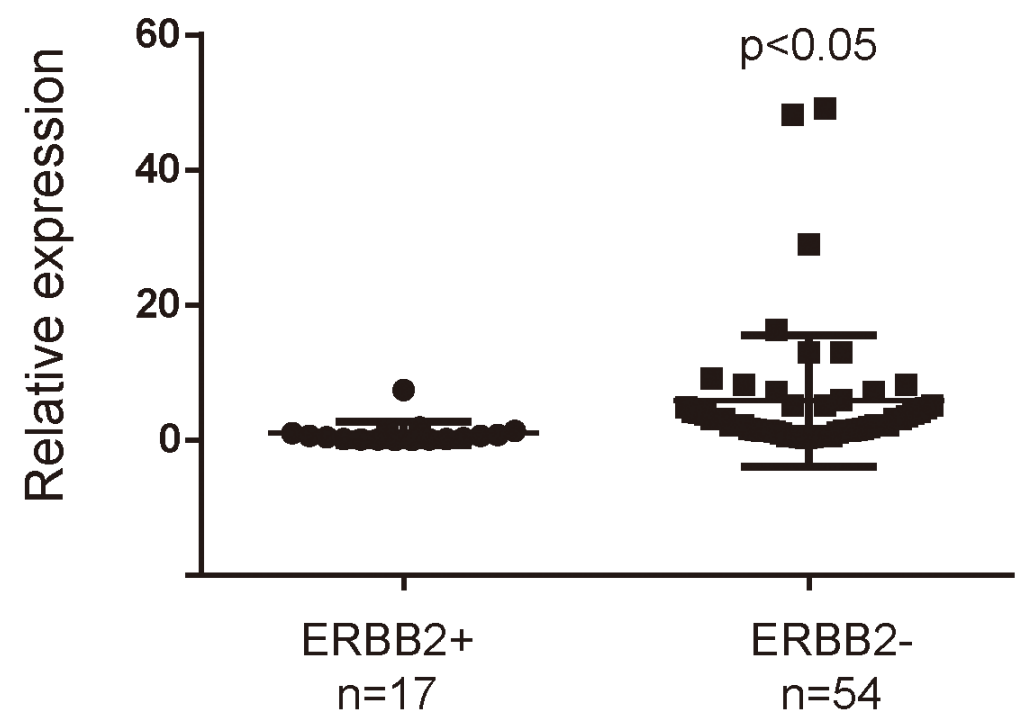

Figure 6: MiR-3622b-5p is down-regulated in ERBB2-positive cancer tissues. The miR-3622b-5p expression was suppressed in a majority of ERBB2-positive breast cancer samples when compared to ERBB2-negative breast cancer samples A. or in a majority of ERBB2-positive gastric cancer samples when compared to ERBB2-negative gastric cancer samples B. The miRNA relative expression levels were normalized to the average value of ERBB2-positive breast cancer samples (A) or ERBB2-positive gastric cancer samples (B). 


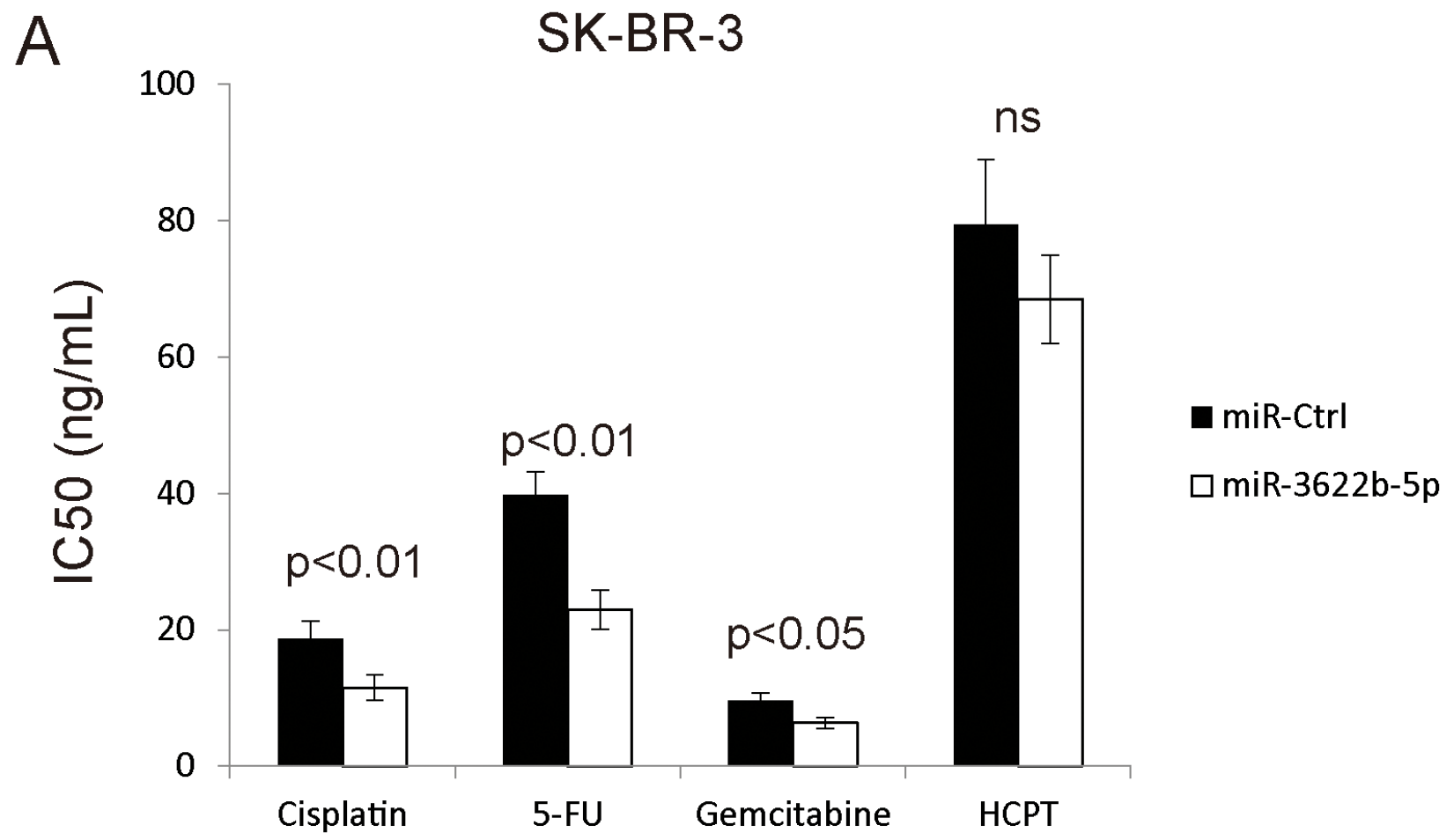

SNU-216

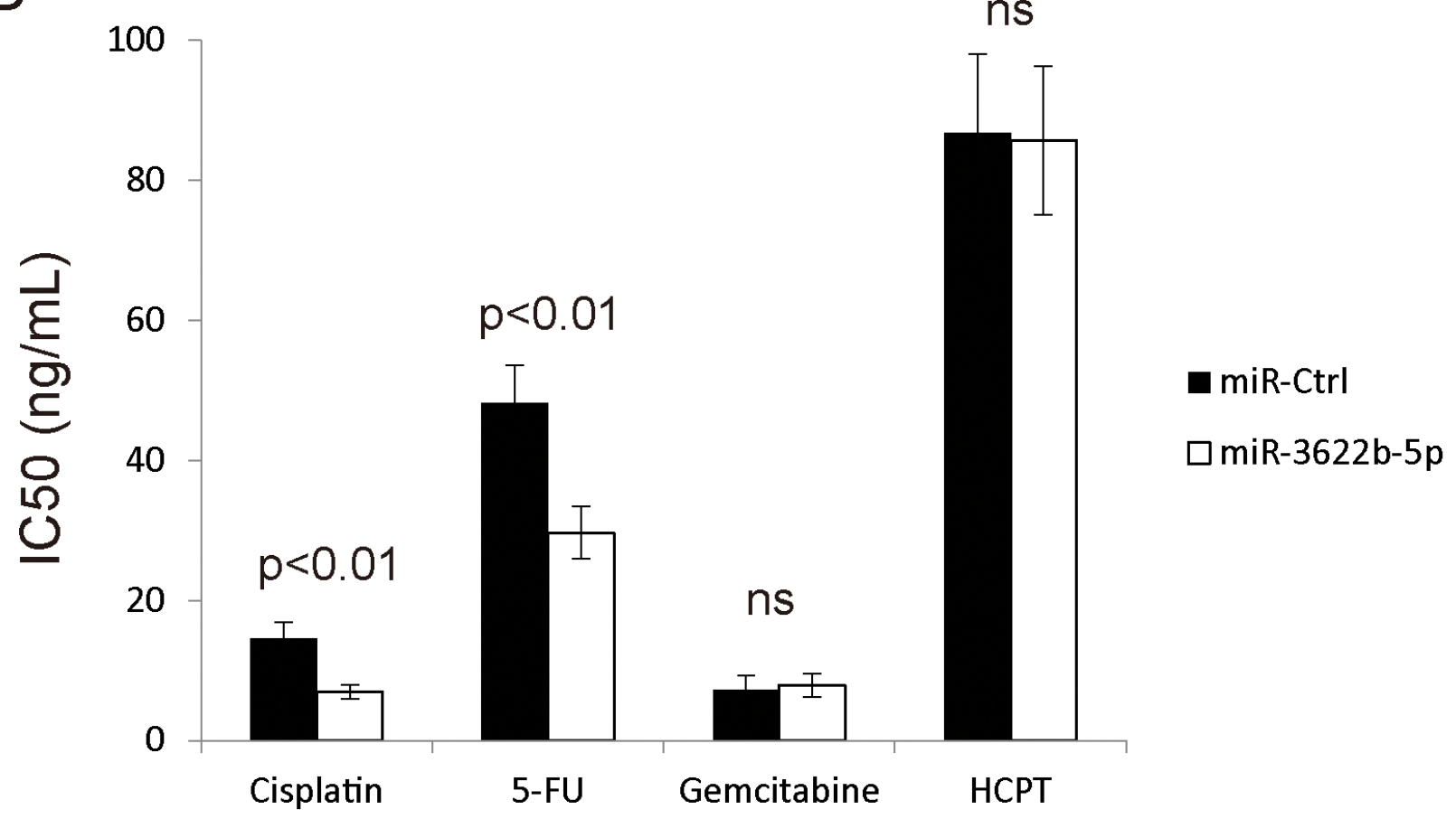

Figure 7: MiR-3622b-5p sensitizes cells to chemotherapy drugs. Over-expression of miR-3622b-5p in SK-BR-3 breast cancer cells A. or SNU-216 gastric cancer cells B. significantly increased cells' sensitivity to cisplatin and 5-fluorouracil (5-FU) compared to control miRNA. Cells were treated with chemotherapeutic drugs $24 \mathrm{~h}$ after miR-3622b-5p transfection and the cell viability was assessed $48 \mathrm{~h}$ after chemotherapeutic drugs treatment. 5-FU, 5-fluorouracil. HCPT, hydroxy camptothecin. ns, no significance. 


\section{MATERIALS AND METHODS}

\section{Clinical samples}

A total of 112 breast cancer patients and 71 gastric cancer patients recruited by the First Affiliated Hospital of Nanjing Medical University from 2013 to 2016 were included in this experiment. We collected 117 samples of cancer tissues and 30 of adjacent normal tissues, 71 of gastric cancer tissues and 30 of adjacent normal tissues. All tissues were histopathologically confirmed by a pathologist who selected areas of higher tumor cell density for RNA isolation and immunohistochemistry (IHC). All the samples were pathologically examined and stored in liquid nitrogen for miRNA analysis. Ethical approval for the study was granted by the Clinical Research Ethics Committee, Nanjing Medical University. Written informed consent was taken from each participant.

\section{Cell culture}

SK-BR-3 human breast cancer cell lines, SNU216 human gastric cancer cell lines, HEK-293T cell lines and MCF-10A normal human mammary epithelial cells were purchased from the Cell Bank of Shanghai (Shanghai, China). Cells were routinely cultured in RPMI 1640 medium or Dulbecco minimum essential medium (DMEM) medium, supplemented with $10 \%$ fetal bovine serum (Hyclone, Logan, UT, USA), at $37^{\circ} \mathrm{C}$ in a humidified atmosphere with $5 \% \mathrm{CO}_{2}$.

\section{Quantitative real-time PCR analysis for miRNA}

Breast cancer tissues and cells were isolated with Trizol reagent (Invitrogen, Carlsbad, CA) and miRNA fractions were further purified by mirVana ${ }^{\mathrm{TM}}$ miRNA isolation kit (Ambion, Austin, TX). The concentration and purity of RNA samples were determined spectroscopically. Expression of mature miRNA was assayed using stem-loop RT, followed by real-time PCR analysis. The SYBR and U6 genes were used for detecting the gene amplification and normalizing each sample, respectively. The primers of reverse transcription and polymerase chain reaction were purchased from RiboBio Co., Ltd (Guangzhou, China) named Bulge-Loop ${ }^{\mathrm{TM}}$ miRNA qRT-PCR Primer Set as previously described [31]. QRT-PCR was performed according to the protocol of primer sets. PCR amplification was detected by the level of fluorescence emitted by SYBR Green (SYBR ${ }^{\circledR}$ Premix Ex Taq ${ }^{\mathrm{TM}}$ II, TaKaRa) intercalated into double-stranded DNA [31]. The $\Delta \mathrm{Ct}$ method was used for miRNA expression analysis of biopsy specimens. First, the cycle number at the threshold level of fluorescence $(\mathrm{Ct})$ in each sample was determined. Next, the $\Delta \mathrm{Ct}$ value was calculated to show the difference between $\mathrm{Ct}$ value of miR$3622 b-5 p$ and $\mathrm{Ct}$ value of U6: $\Delta \mathrm{Ct}=\mathrm{Ct}(\mathrm{miR}-3622 \mathrm{~b}-5 \mathrm{p})$ $\mathrm{Ct}(\mathrm{U} 6)$. The fold-change for miR-3622b-5p was calculated using $2^{-\Delta \Delta C t}$ method. PCR was performed in triplicate.

\section{RhoA and Rac1 activation assay}

In RhoA and Rac1 activation assays (Cytoskeleton Inc., Denver, CO, USA), cells were seeded into 6-well plates and transfected with miR-3622b-5p mimic or miRNA mimic control. The experiments were then performed according to the manufacturer's protocol. RhoA and Rac1 activation assay was performed in triplicate.

\section{In vitro drug sensitivity assay}

SK-BR-3 or SNU-216 cancer cells were seeded into 6 -well plates $\left(6 \times 10^{5}\right.$ cells/well $), 100 \mathrm{nmol} / \mathrm{L} \mathrm{miR}$ $3622 \mathrm{~b}-5 \mathrm{p}$ mimic or $100 \mathrm{nmol} / \mathrm{L}$ miRNA mimic control was transfected by Lipofectamine 2000 (Invitrogen, Long Island, NY, USA) according to the manufacturer's protocol, respectively. The miR-3622b-5p mimic and miRNA mimic control were chemically synthesized by Shanghai GenePharma Company (Shanghai, China). Twenty four hours after transfection, cells were seeded into 96-well plates $\left(5 \times 10^{3}\right.$ cells/well). Another forty eight hours after drug administration, cell viability was assessed by 3-(4,5-dimethylthiazol-2-yl)-2,5-diphenyltetrazolium bromide (MTT) assay. The absorbance at 490 $\mathrm{nm}$ in each well was read on a spectrophotometer. The concentration at which drugs produced $50 \%$ inhibition of growth (IC50) was estimated by the relative survival curve. Three independent experiments were performed in quadruplicate.

\section{Dual-luciferase activity assay}

The 3'-UTR of human ERBB2 containing the putative target site of the miR-3622b-5p was synthesized and placed at the $X b a \mathrm{I}$ site in the pGL3-control vector (Promega, Madison, WI) by Integrated Biotech Solutions Co., Ltd (Shanghai, China). Twenty four hours before transfection, cells were seeded into 24 -well plates $\left(1.5 \times 10^{5}\right.$ cells/well). Then, $200 \mathrm{ng}$ of pGL3-ERBB2-3'-UTR-WT or pGL3-ERBB2-3'-UTR-WT-del plus 80 ng pRL-TK (Promega) were transfected with 60 pmol miR-3622b-5p mimic or miRNA mimic control by using Lipofectamine 2000 (Invitrogen) according to the manufacturer's protocol. Luciferase activity was measured twenty four hours after transfection using Dual Luciferase Reporter Assay System (Promega). Firefly luciferase activity was normalized to renilla luciferase activity for each transfected well. Three independent experiments were performed.

\section{Western blot analysis}

SK-BR-3or SNU-216 cancer cells were placed into 6 -well plates $\left(6 \times 10^{5}\right.$ cells $/$ well $)$. Seventy two hours after the transfection with miR-3622b-5p mimic or miRNA mimic control, cells were harvested and homogenized with lysis buffer. Total protein was separated by denatured 
$10 \%$ SDS-polyacrylamide gel electrophoresis. Western blot analysis was performed [32]. The primary antibodies for ERBB2, S6, Phospho-S6, â-actin and GAPDH were purchased from Cell Signaling Technology (Danvers, MA). The primary antibody for ERBB3 was purchased from Proteintech Wuhan Sanying (Wuhan, China). Protein levels were normalized to â-actin or GAPDH.

\section{Clonogenic assay}

SK-BR-3 or SNU-216 cells were transfected with miR-3622b-5p mimic (with/without ERBB2 lacking 3'UTR) and placed into 6-well plates (1000 cells/well), incubated at $37^{\circ} \mathrm{C}$ for 2 weeks, fixed and stained with crystal violet. The mean $\pm \mathrm{SD}$ number of colonies was counted under a microscope from three independent replicates.

\section{Apoptosis assay}

SK-BR-3 or SNU-216 cells were placed into 6-well plates $\left(6 \times 10^{5}\right.$ cells /well). Forty eight hours after the transfection with $\mathrm{miR}-3622 \mathrm{~b}-5 \mathrm{p}$ mimic (with/without ERBB2 lacking 3 '-UTR), flow cytometry was used to detect the apoptosis of transfected cells by determining the amount of AnnexinV-positive and PI-negative cells.

\section{Statistical analysis}

Each experiment was repeated for at least 3 times. Numerical data were presented as mean \pm SD. The difference between means was analyzed with Student's t-test. All statistical analyses were performed using SPSS 13.0 software (Chicago, IL). Differences were considered significant when $p<0.05$.

\section{ACKNOWLEDGMENTS}

We thank Mr. Yongke Cao (Nanjing Medical University) for proofreading the manuscript and correcting grammatical errors.

\section{CONFLICTS OF INTEREST}

We state no conflicts of interest. The funding bodies had no role in study design, data collection and analysis, decision to publish or preparation of the manuscript. The contents have not been published by or submitted to any other journal. No part of this manuscript has been included in any other manuscript.

\section{FUNDING}

This work was supported by grants from the National Natural Science Foundation of China (81370516 to Wenfang Cheng, 81472703 to Yichao Zhu, 81672400 to Wei Zhu).

\section{Author contributions}

Study design: WZ, YZ, PL. Clinical studies: ML, TW, MH. Experimental studies: ZH, LZ, HZ. Data analysis: WC, TY. Manuscript writing: YZ.

\section{REFERENCES}

1. Yu D, and Hung MC. Overexpression of ErbB2 in cancer and ErbB2-targeting strategies. Oncogene. 2000; 19:6115-6121.

2. Schuell B, Gruenberger T, Scheithauer W, Zielinski C, and Wrba F. HER 2/neu protein expression in colorectal cancer. BMC Cancer. 2006; 6:123.

3. Eltze E, Wulfing C, Von Struensee D, Piechota H, Buerger $\mathrm{H}$, and Hertle L. Cox-2 and Her2/neu co-expression in invasive bladder cancer. Int J Oncol. 2005; 26:1525-1531.

4. McKenzie SJ, DeSombre KA, Bast BS, Hollis DR, Whitaker RS, Berchuck A, Boyer CM, and Bast RC Jr. Serum levels of HER-2 neu (C-erbB-2) correlate with overexpression of p185neu in human ovarian cancer. Cancer. 1993; 71:3942-3946.

5. Hetzel DJ, Wilson TO, Keeney GL, Roche PC, Cha SS, and Podratz KC. HER-2/neu expression: a major prognostic factor in endometrial cancer. Gynecol Oncol. 1992; 47:179-185.

6. Hirashima N, Takahashi W, Yoshii S, Yamane T, and Ooi A. Protein overexpression and gene amplification of c-erb B-2 in pulmonary carcinomas: a comparative immunohistochemical and fluorescence in situ hybridization study. Mod Pathol. 2001; 14:556-562.

7. Mitra AB, Murty VV, Pratap M, Sodhani P, and Chaganti RS. ERBB2 (HER2/neu) oncogene is frequently amplified in squamous cell carcinoma of the uterine cervix. Cancer Res. 1994; 54:637-639.

8. Beckhardt RN, Kiyokawa N, Xi L, Liu TJ, Hung MC, el-Naggar AK, Zhang HZ, and Clayman GL. HER-2/neu oncogene characterization in head and neck squamous cell carcinoma. Arch Otolaryngol Head Neck Surg. 1995; 121:1265-1270.

9. Slamon DJ, Godolphin W, Jones LA, Holt JA, Wong SG, Keith DE, Levin WJ, Stuart SG, Udove J, Ullrich A, and Press MF. Studies of the HER-2/neu proto-oncogene in human breast and ovarian cancer. Science. 1989; 244:707-712.

10. Gravalos $\mathrm{C}$, and Jimeno A. HER2 in gastric cancer: a new prognostic factor and a novel therapeutic target. Ann Oncol. 2008; 19:1523-1529.

11. Hudis CA. Drug therapy: Trastuzumab - Mechanism of action and use in clinical practice. New Engl J Med. 2007; 357:39-51.

12. Son HS, Shin YM, Park KK, Seo KW, Yoon KY, Jang HK, Lee SH, Yang SI, and Kim JH. Correlation between HER2 Overexpression and Clinicopathological Characteristics in 
Gastric Cancer Patients Who Have Undergone Curative Resection. J Gastric Cancer. 2014; 14:180-186.

13. Nahta R, and Esteva FJ. Trastuzumab: triumphs and tribulations. Oncogene. 2007; 26:3637-3643.

14. Niu J, Xue A, Chi Y, Xue J, Wang W, Zhao Z, Fan M, Yang $\mathrm{CH}$, Shao ZM, Pfeffer LM, Wu J, and Wu ZH. Induction of miRNA-181a by genotoxic treatments promotes chemotherapeutic resistance and metastasis in breast cancer. Oncogene. 2016; 35:1302-1313.

15. Xue J, Chi Y, Chen Y, Huang S, Ye X, Niu J, Wang W, Pfeffer LM, Shao ZM, Wu ZH, and Wu J. MiRNA-621 sensitizes breast cancer to chemotherapy by suppressing FBXO11 and enhancing p53 activity. Oncogene. 2016; 35:448-458.

16. Yuan Y, Anbalagan D, Lee LH, Samy RP, Shanmugam MK, Kumar AP, Sethi G, Lobie PE, and Lim LH. ANXA1 inhibits miRNA-196a in a negative feedback loop through NF-kB and C-Myc to reduce breast cancer proliferation. Oncotarget. 2016; 7:27007-20. doi: 10.18632/ oncotarget.8875.

17. Chen H, Sun JG, Cao XW, Ma XG, Xu JP, Luo FK, and Chen ZT. Preliminary validation of ERBB2 expression regulated by miR-548d-3p and miR-559. Biochem Biophys Res Commun. 2009; 385:596-600.

18. Wang S, Huang J, Lyu H, Lee CK, Tan J, Wang J, and Liu B. Functional cooperation of miR-125a, miR-125b, and miR-205 in entinostat-induced downregulation of erbB2/ erbB3 and apoptosis in breast cancer cells. Cell Death Dis. 2013; 4:e556.

19. He XH, Zhu W, Yuan P, Jiang S, Li D, Zhang HW, and Liu MF. miR-155 downregulates ErbB2 and suppresses ErbB2induced malignant transformation of breast epithelial cells. Oncogene. 2016; 35:6015-6025.

20. Schmitt DC, Madeira da Silva L, Zhang W, Liu Z, Arora R, Lim S, Schuler AM, McClellan S, Andrews JF, Kahn AG, Zhou M, Ahn EY, and Tan M. ErbB2-intronic microRNA-4728: a novel tumor suppressor and antagonist of oncogenic MAPK signaling. Cell Death Dis. 2015; 6:e1742.

21. Liu D, Yang Z, Wang T, Yang Z, Chen H, Hu Y, Hu C, Guo L, Deng Q, Liu Y, Yu M, Shi M, Du N, et al. beta2-AR signaling controls trastuzumab resistance-dependent pathway. Oncogene. 2016; 35:47-58.

22. Johnson E, Seachrist DD, DeLeon-Rodriguez CM, Lozada KL, Miedler J, Abdul-Karim FW, and Keri RA. HER2/ ErbB2-induced breast cancer cell migration and invasion require p120 catenin activation of Rac1 and Cdc42. J Biol Chem. 2010; 285:29491-29501.

23. Tornillo G, Bisaro B, Camacho-Leal Mdel P, Galie M, Provero P, Di Stefano P, Turco E, Defilippi P, and Cabodi S. p130Cas promotes invasiveness of three-dimensional ErbB2-transformed mammary acinar structures by enhanced activation of mTOR/p70S6K and Rac1. Eur J Cell Biol. 2011; 90:237-248.

24. Kong Y, Si L, Li Y, Wu X, Xu X, Dai J, Tang H, Ma M, Chi Z, Sheng X, Cui C, and Guo J. Analysis of mTOR Gene Aberrations in Melanoma Patients and Evaluation of Their Sensitivity to PI3K-AKT-mTOR Pathway Inhibitors. Clin Cancer Res. 2016; 22:1018-1027.

25. De Mattos-Arruda L, Bottai G, Nuciforo PG, Di Tommaso L, Giovannetti E, Peg V, Losurdo A, PerezGarcia J, Masci G, Corsi F, Cortés J, Seoane J, Calin GA, et al. MicroRNA-21 links epithelial-to-mesenchymal transition and inflammatory signals to confer resistance to neoadjuvant trastuzumab and chemotherapy in HER2positive breast cancer patients. Oncotarget. 2015; 6:3726937280. doi: 10.18632/oncotarget.5495.

26. Ferracin M, Bassi C, Pedriali M, Pagotto S, D'Abundo L, Zagatti B, Corra F, Musa G, Callegari E, Lupini L, Volpato S, Querzoli P, and Negrini M. miR-125b targets erythropoietin and its receptor and their expression correlates with metastatic potential and ERBB2/HER2 expression. Mol Cancer. 2013; 12:130.

27. Ye X, Bai W, Zhu H, Zhang X, Chen Y, Wang L, Yang A, Zhao J, and Jia L. MiR-221 promotes trastuzumabresistance and metastasis in HER2-positive breast cancers by targeting PTEN. BMB Rep. 2014; 47:268-273.

28. Huang D, Duan H, Huang H, Tong X, Han Y, Ru G, Qu $\mathrm{L}$, Shou C, and Zhao Z. Cisplatin resistance in gastric cancer cells is associated with HER2 upregulation-induced epithelial-mesenchymal transition. Sci Rep. 2016; 6:20502.

29. T ALT, AlSayed A, Alawadi S, Ibrahim M, Ashour W, Jaafar H, Abulkhair O, H ALA, Khalid H, Ajarim D, and Gulf Oncology Research Group (GORG-001). A multicenter prospective phase II trial of neoadjuvant epirubicin, cyclophosphamide, and 5-fluorouracil (FEC100) followed by cisplatin-docetaxel with or without trastuzumab in locally advanced breast cancer. Cancer Chemother Pharmacol. 2016; 77:147-153.

30. Weissinger F, Reymond M, Dumke K, and Kruger M. Successful treatment of a patient with HER2-positive metastatic gastric cancer with third-line combination therapy with irinotecan, 5-fluorouracil, leucovorin and trastuzumab (FOLFIRI-T). Onkologie. 2011; 34:548-551.

31. Zhao DS, Chen Y, Jiang H, Lu JP, Zhang G, Geng J, Zhang Q, Shen JH, Zhou X, Zhu W, and Shan QJ. Serum miR-210 and miR-30a expressions tend to revert to fetal levels in Chinese adult patients with chronic heart failure. Cardiovasc Pathol. 2013; 22:444-450.

32. Zhu Y, Shen T, Liu J, Zheng J, Zhang Y, Xu R, Sun C, Du J, Chen Y, and Gu L. Rab35 is required for Wnt5a/Dvl2induced Rac1 activation and cell migration in MCF-7 breast cancer cells. Cell Signal. 2013; 25:1075-1085. 